\title{
Substituent-effect of Imidazolium Ionic Liquid: a Potential Strategy for High Coulombic Efficiency Al Battery
}

Congrong Yang, Suli Wang,* Xiaoming Zhang, Qiang Zhang, Wenjia Ma, Shansheng Yu and Gongquan Sun*

Division of Fuel Cell \& Battery, Dalian National Laboratory for Clean Energy, Dalian Institute of Chemical Physics, Chinese Academy of Sciences, 457 Zhongshan Road, Dalian 116023, PR China.gqsun@dicp.ac.cn; suliwang@dicp.ac.cn

\section{${ }^{1}$ HNMR spectra}

${ }^{1} \mathrm{H}$ NMR technology was used to determine the chemical structures of all the imidazolium ionic liquids. ${ }^{1} \mathrm{H}$ NMR spectra were recorded on a Bruker ACIII 400 spectrometer. The chemical structure of ionic liquids could be determined by the ${ }^{1} \mathrm{H}$ NMR spectra $\left(\mathrm{D}_{2} \mathrm{O}\right.$ as solvent). From Figure S1-S6, it can be seen that the highly pure imidazolium ionic liquids were successfully synthesized. 


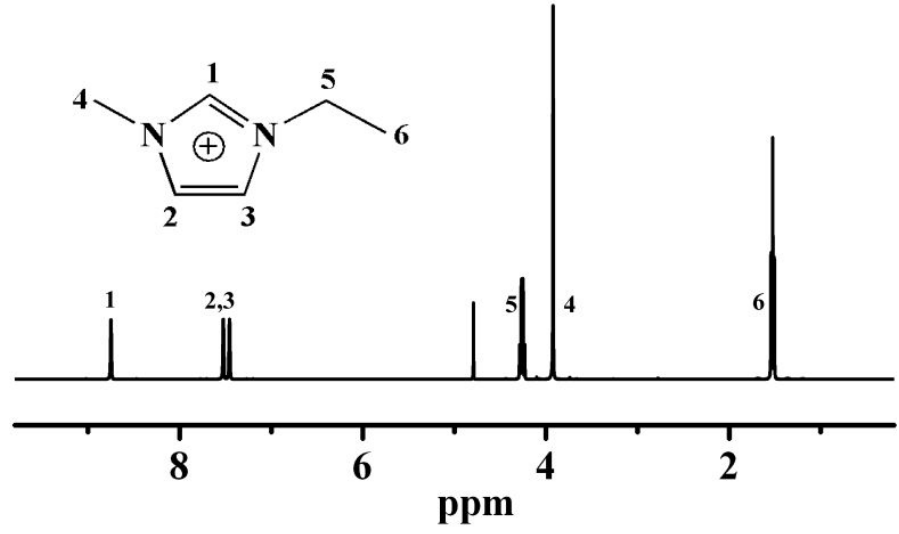

Figure S1 ${ }^{1} \mathrm{H}$ NMR spectra of [MEIM]Cl.

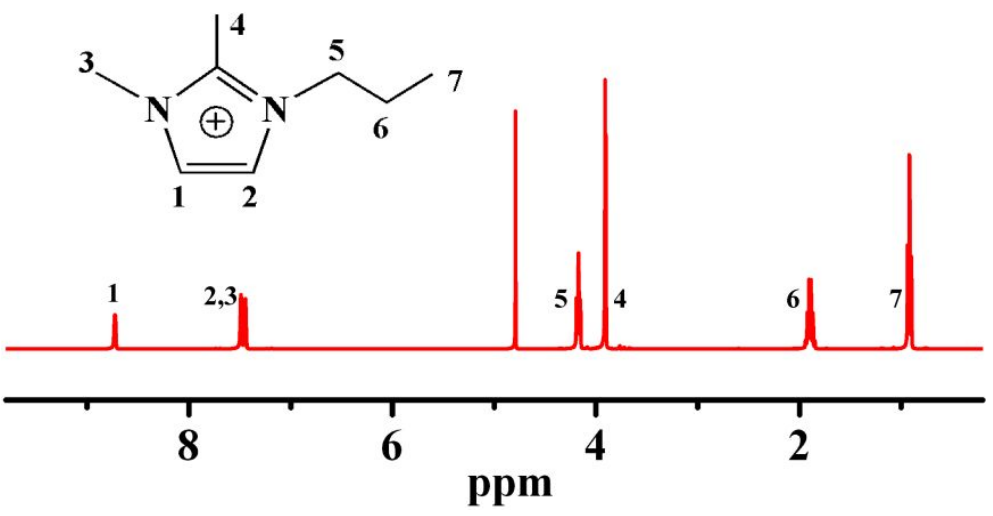

Figure S2 ${ }^{1} \mathrm{H}$ NMR spectra of [MPIM]Cl.

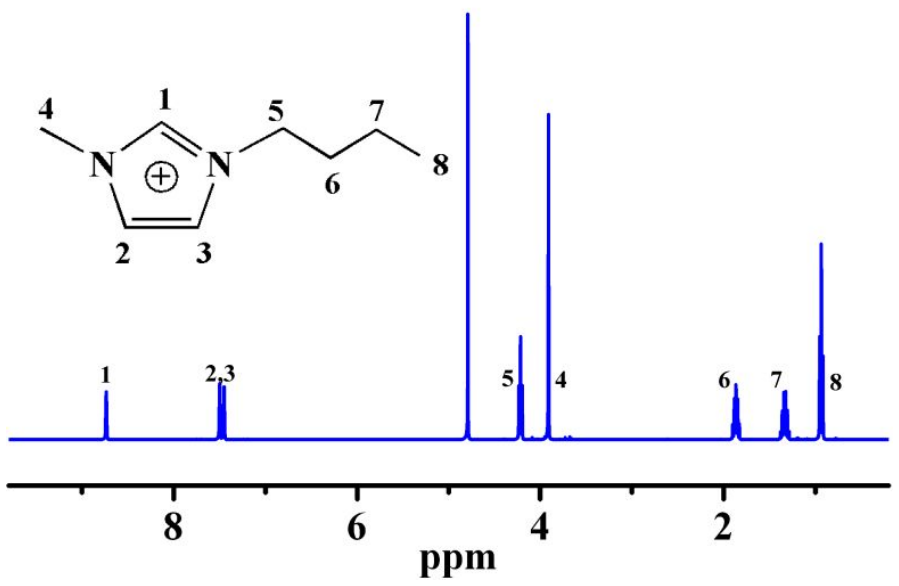

Figure S3 ${ }^{1} \mathrm{H}$ NMR spectra of $[\mathrm{MBIM}] \mathrm{Cl}$. 


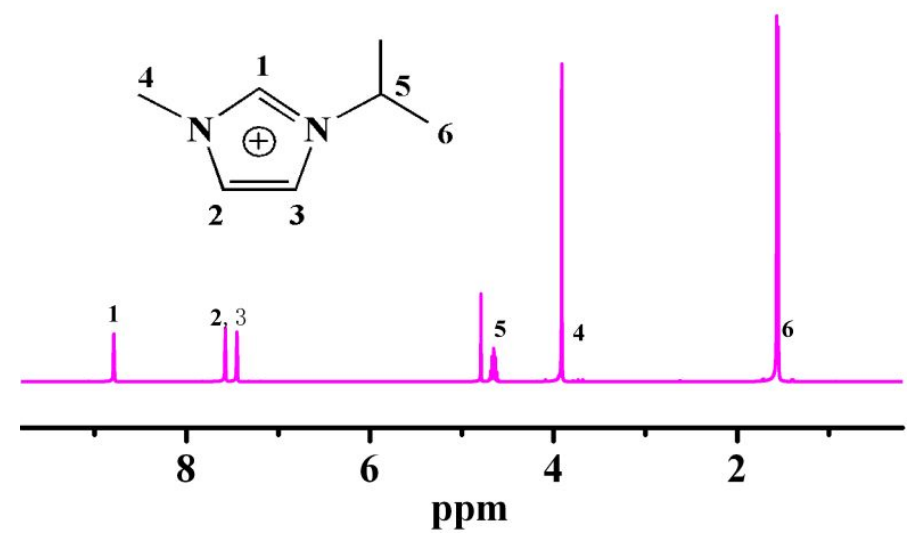

Figure S4 ${ }^{1} \mathrm{H}$ NMR spectra of [MIPIM]Cl.

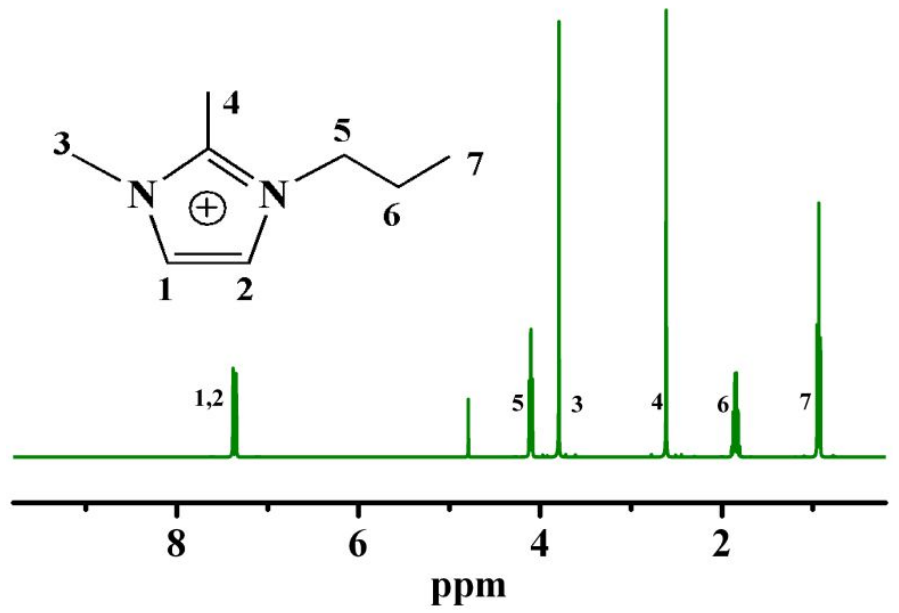

Figure S5 ${ }^{1} \mathrm{H}$ NMR spectra of [DMPIM]Cl.

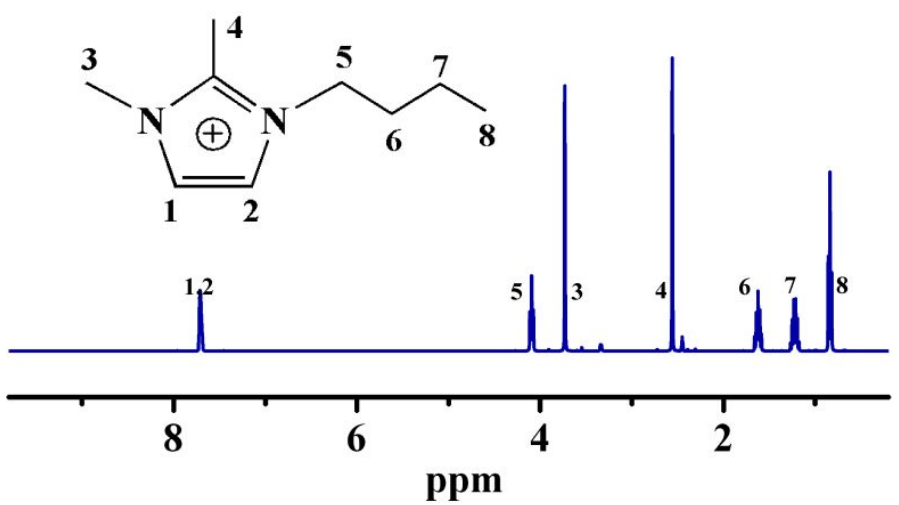

Figure S6 ${ }^{1} \mathrm{H}$ NMR spectra of [DMBIM]Cl. 


\section{Synthesis of imidazolium ionic liquid}

1-Methyl-3-ethylimidazolium bromide ([MEIM]Br) was synthesized by the nucleophilic reaction between 1- methylimidazole and bromethyl at room temperature.

1-Methyl-3-ethylimidazolium bis(trifluoromethane)sulfonimide ([MEIM]TFSI) was obtained by the substitution reaction between [MEIM]Br and LiTFSI.

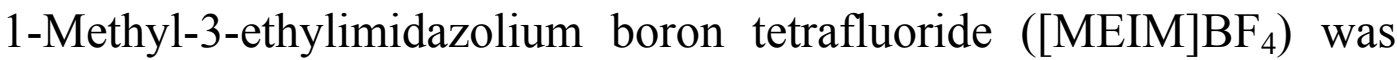
obtained as follows: $\mathrm{Ag}_{2} \mathrm{O}$ was stirred with $48 \%$ aqueous $\mathrm{HBF}_{4}$ in water until the $\mathrm{Ag}_{2} \mathrm{O}$ had reacted completely giving a clear solution. [MEIM]Br dissolved in water was then added to the solution. After $2 \mathrm{~h}$, the $\mathrm{AgCl}$ precipitate was filtered off, and the filtrate was concentrated in vacuum. The resulting clear, colorless solution was dried overnight in a vacuum oven .

\section{Electrochemical properties of electrolytes}

The properties of electrolytes using different imidazolium ionic liquids with $\mathrm{Br}^{-}$or $\mathrm{Cl}^{-}$anion were investigated in detail. The mole ratio of $\mathrm{AlCl}_{3} /[\mathrm{MEIM}] \mathrm{Br}$ and $\mathrm{AlCl}_{3} /[\mathrm{MEIM}] \mathrm{Cl}$ in the electrolytes is controlled at 1.3:1. Figure S7 and Figure S8 show the conductivities and CV measurements of $\mathrm{AlCl}_{3} /[\mathrm{MEIM}] \mathrm{Br}$ and $\mathrm{AlCl}_{3} /[\mathrm{MEIM}] \mathrm{Cl}$ electrolytes, respectively. From Figure S7 and Figure S8, it can be seen that $\mathrm{AlCl}_{3} /[\mathrm{MEIM}] \mathrm{Cl}$ electrolyte possesses a higher conductivity and a wider 
electrochemical window than that of $\mathrm{AlCl}_{3} /[\mathrm{MEIM}] \mathrm{Br}$ electrolyte.

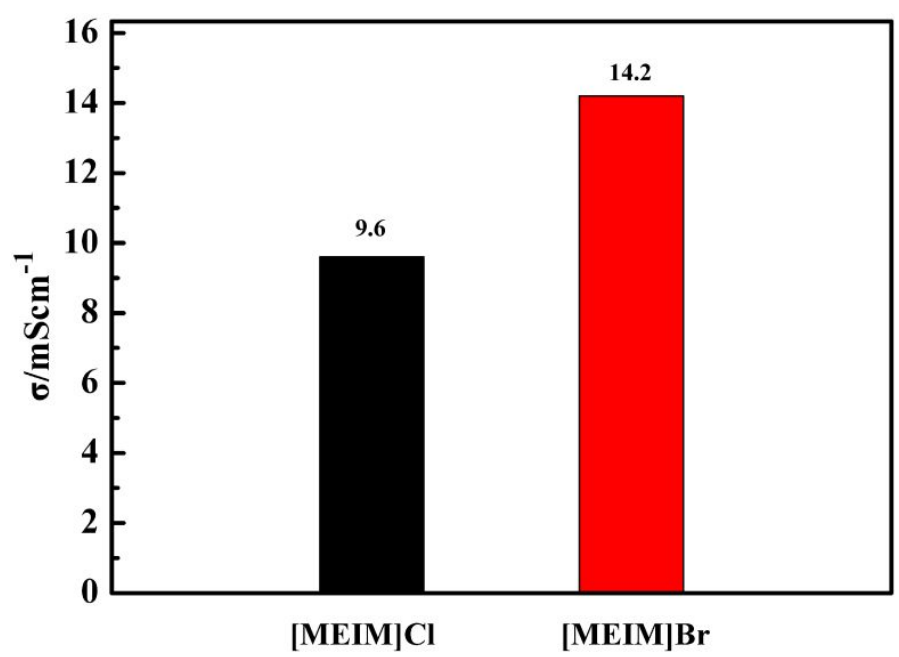

Figure $\mathbf{S} 7$ Conductivities of $\mathrm{AlCl}_{3} /[\mathrm{MEIM}] \mathrm{Cl}$ and $\mathrm{AlCl}_{3} /[\mathrm{MEIM}] \mathrm{Br}$.

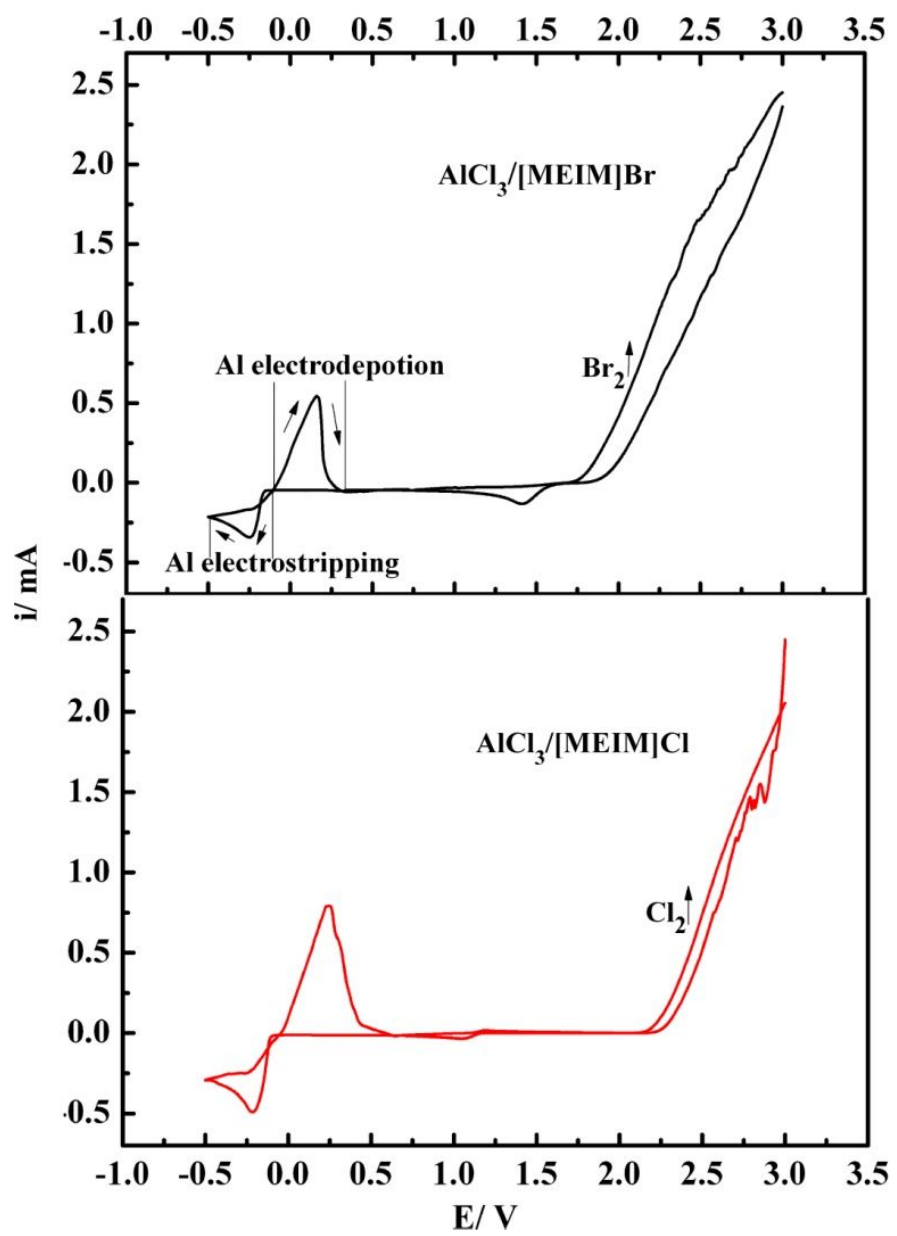

Figure $\mathbf{S 8 ~ C V}$ measurements of $\mathrm{AlCl}_{3} /[\mathrm{MEIM}] \mathrm{Cl}$ and $\mathrm{AlCl}_{3} /[\mathrm{MEIM}] \mathrm{Br}$. 
The mole ratio of $\mathrm{AlCl}_{3}$ to $[\mathrm{MEIM}] \mathrm{BF}_{4}$ or [MEIM]TFSI must be controlled below $0.5: 1$, or gel would form quickly. The conductivity of $\mathrm{AlCl}_{3} /[\mathrm{MEIM}] \mathrm{TFSI}$ electrolyte with the mole ration is $0.49: 1$ is only 2.1 $\mathrm{mScm}^{-1}$, and $\mathrm{CV}$ measurement of this electrolyte is show as Figure S9. It can be seen that there is no electrodeposition/electrostripping activity of aluminium and the electrochemical window is below $1.6 \mathrm{~V}$, showing a poor property.

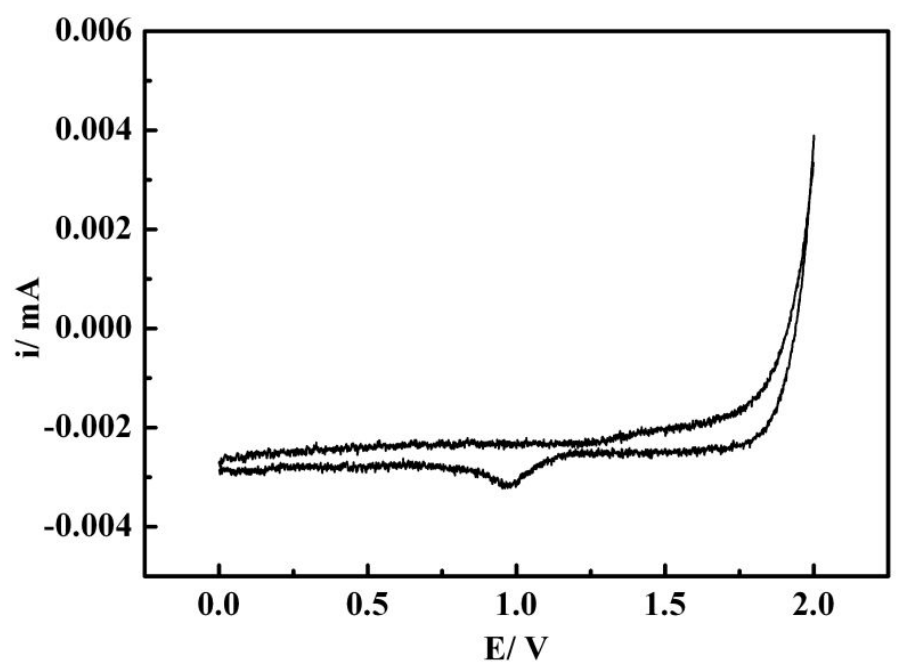

Figure S9 $\mathrm{CV}$ measurement of $\mathrm{AlCl}_{3} /[\mathrm{MEIM}] \mathrm{TFSI}=0.5$ electrolyte: scan rate is 10 $\mathrm{mVs}^{-1}$.

\section{DFT calculation}

DFT calculation is employed to explain the structure-effect relationship of electrolytes. Figure S10 are the optimal chemical structures of different imidazolium cations. From Figure S10, it can be 
seen the symmetry for imidazolium cations with different substituents.

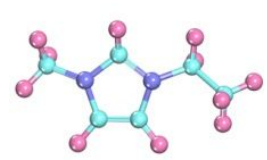

[MEIM] $^{+}$

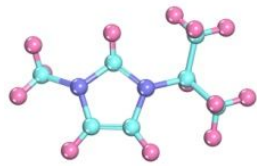

[MIPIM $^{+}$

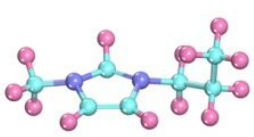

[MPIM $^{+}$

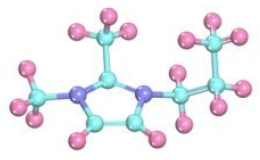

[DMPIM] ${ }^{+}$

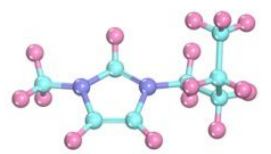

[MBIM $^{+}$

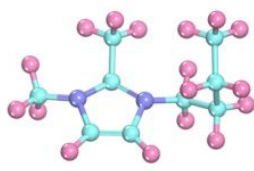

[DMBIM]

Figure S10 Optimal chemical structures of different imidazolium cations.

Substituent effect on electrodeposition/electrostripping reversibility of aluminium

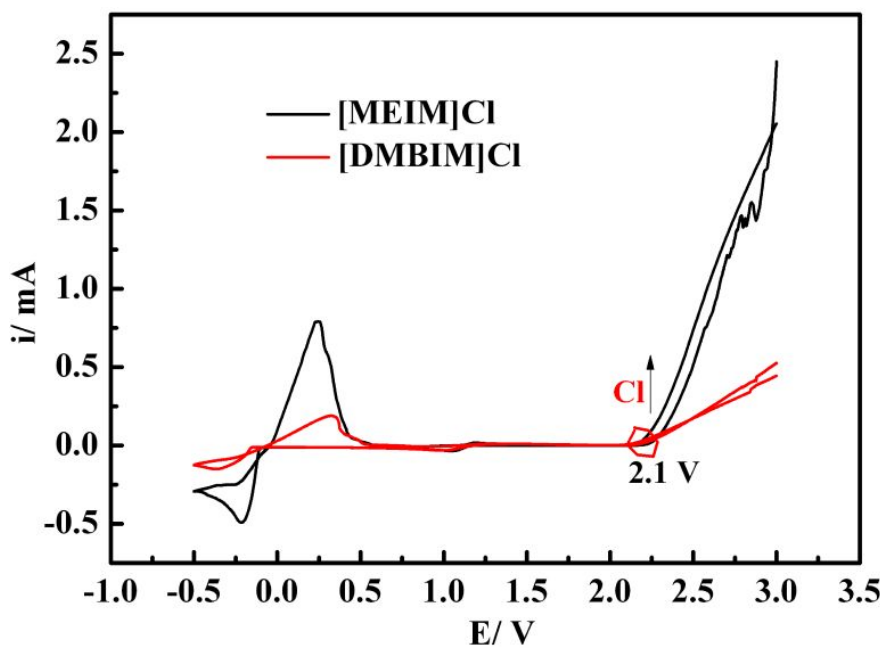

Figure S11 Substituent effects on CV measurements of electrolytes with $20 \mathrm{mVs}^{-1}$ of scan rate. 


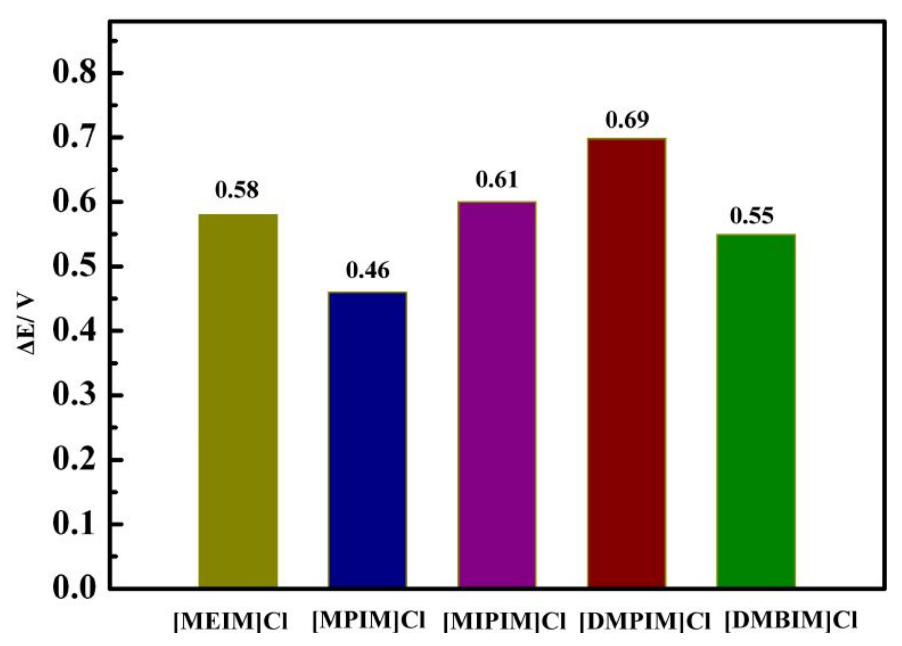

Figure S12 Substituent effects on potential difference between electrodeposition and electrostripping current peak of aluminium.

\section{Ratio effect on the properties of $\mathrm{AlCl}_{3} /[\mathrm{MPIM}] \mathrm{Cl}$ electrolytes}

The ratio of $\mathrm{AlCl}_{3}$ to $[\mathrm{MPIM}] \mathrm{Cl}$ would influence the properties, such as conductivity and electrochemical performance, so the optimum ratio of $\mathrm{AlCl}_{3}$ to $[\mathrm{MPIM}] \mathrm{Cl}$ should be confirmed before assembling the battery. Figure S13 shows the conductivity and CV measurements of electrolytes with different ratios. It can be seen that the conductivity of electrolyte decreases with the ratio of $\mathrm{AlCl}_{3}$ to [MPIM]Cl increases, and electrodeposition/electrostripping reversibility of aluminium in $\mathrm{AlCl}_{3} /[\mathrm{MPIM}] \mathrm{Cl}$ electrolyte with ratio of $1.2: 1$ is comparable to that of this electrolyte with ratio of 1.3:1. 

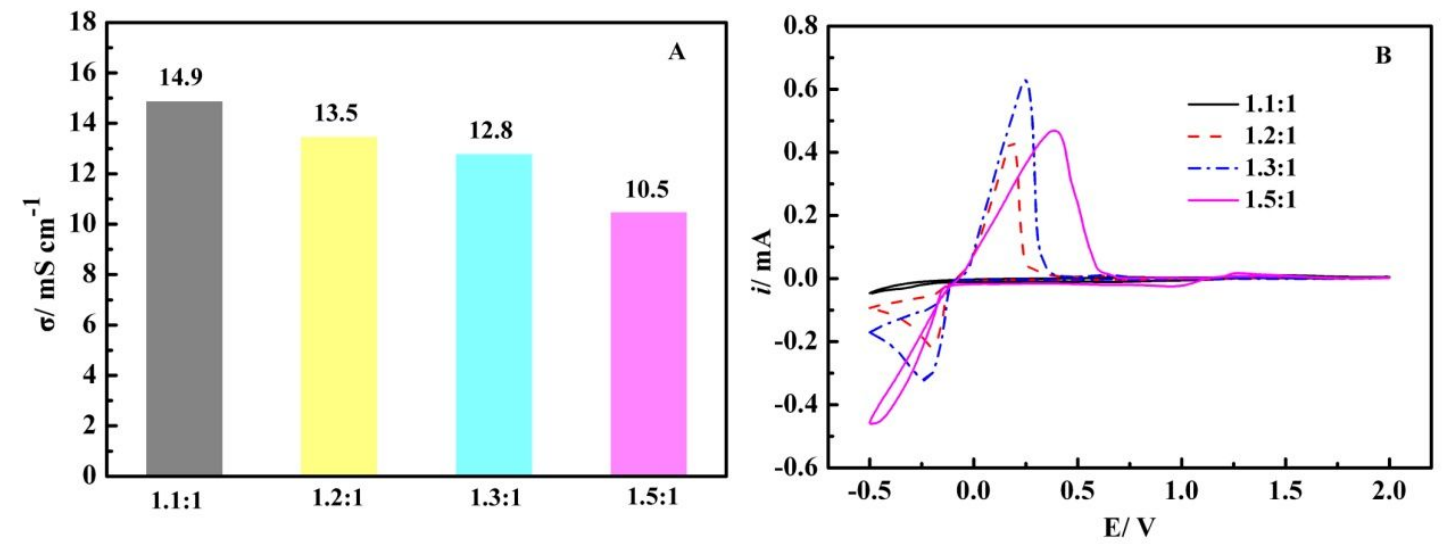

Figure S13 Conductivities and CV measurements of $\mathrm{AlCl}_{3} /[\mathrm{MPIM}] \mathrm{Cl}$ electrolytes with different ratios. (A) conductivities; (B) CV measurements.

\section{Electrochemical stability of $\mathrm{AlCl}_{3} /[\mathrm{MPIM}] \mathrm{Cl}$}

The electrochemical stability of $\mathrm{AlCl}_{3} /[\mathrm{MPIM}] \mathrm{Cl}$ electrolyte is checked by comparing

the resistance and electrodeposition/electrostripping potential of aluminium changes before and after $\mathrm{CV}$ test for 500 cycles. The resistance and the electrodeposition/electrostripping potential of aluminium of electrolyte are nearly unchangeable, indicating a excellent electrochemical stability of $\mathrm{AlCl}_{3}:[\mathrm{MPIM}] \mathrm{Cl}$.

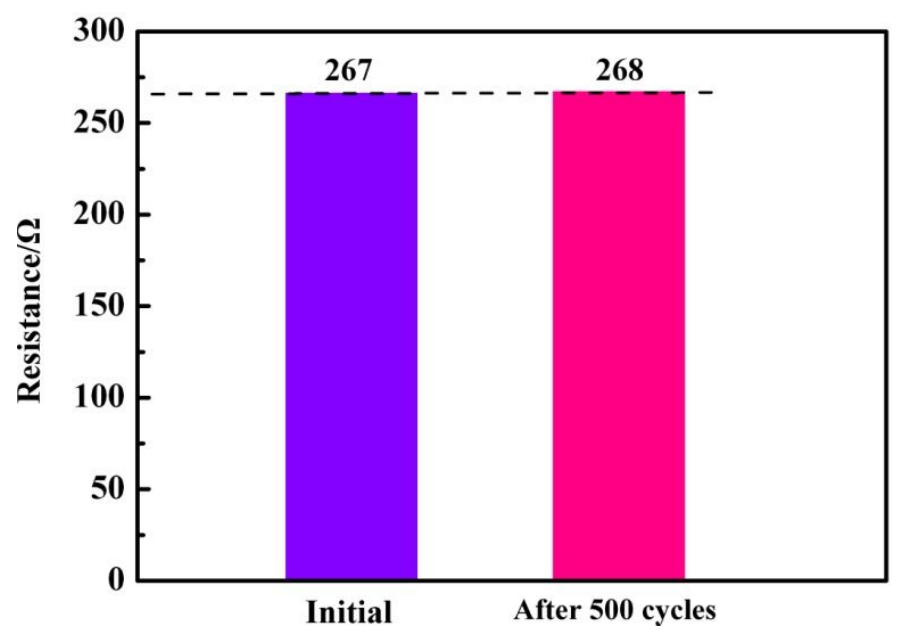

Figure S14 Resistance comparison of of $\mathrm{AlCl}_{3} /[\mathrm{MPIM}] \mathrm{Cl}$ electrolyte before and after electrochemical stability test. 


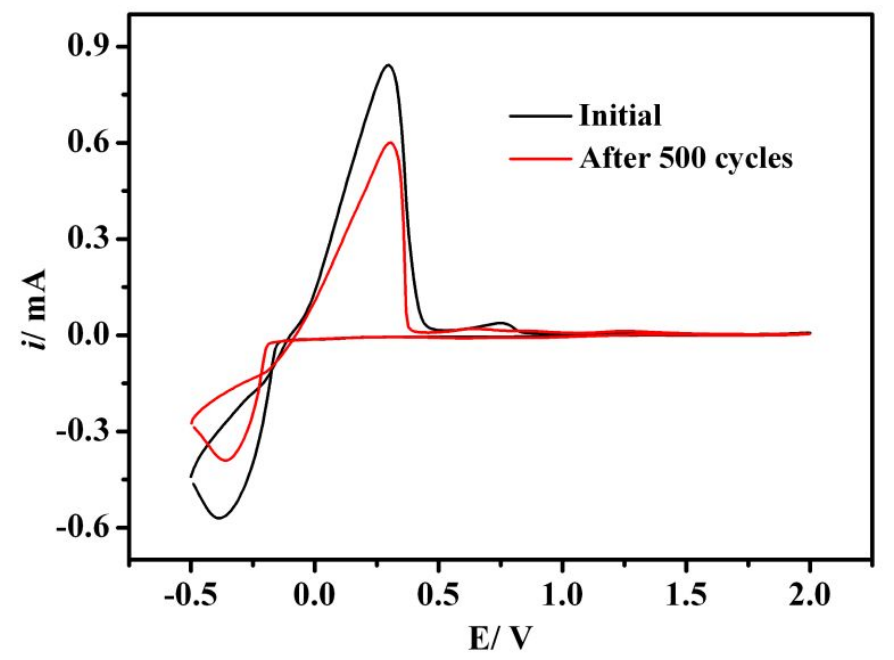

Figure S15 CV comparison of of $\mathrm{AlCl}_{3} /[\mathrm{MPIM}] \mathrm{Cl}$ electrolyte before and after electrochemical stability test.

\section{SEM of Al}

$\mathrm{Al}_{2} \mathrm{Cl}_{7}{ }^{-}$is considered to act as the electrochemical active material in $\mathrm{Al}(\mathrm{III})$ reduction at the anode, but it would causes corrosion on $\mathrm{Al}$ anode, especially with higher concentration. SEM was used to judge the corrosion degree of $\mathrm{Al}$ in $\mathrm{AlCl}_{3} /[\mathrm{MPIM}] \mathrm{Cl}$ electrolyte with mole ratio of 1.3:1 after CV different cycles. It can be seen that there is almost no corrosion on $\mathrm{Al}$ after 200 cycles and only a slight corrosion on $\mathrm{Al}$ after 500 cycles. That is to say, the $\mathrm{AlCl}_{3} /[\mathrm{MPIM}] \mathrm{Cl}$ shows an excellent performance, indicating a potential application for AIBs. 

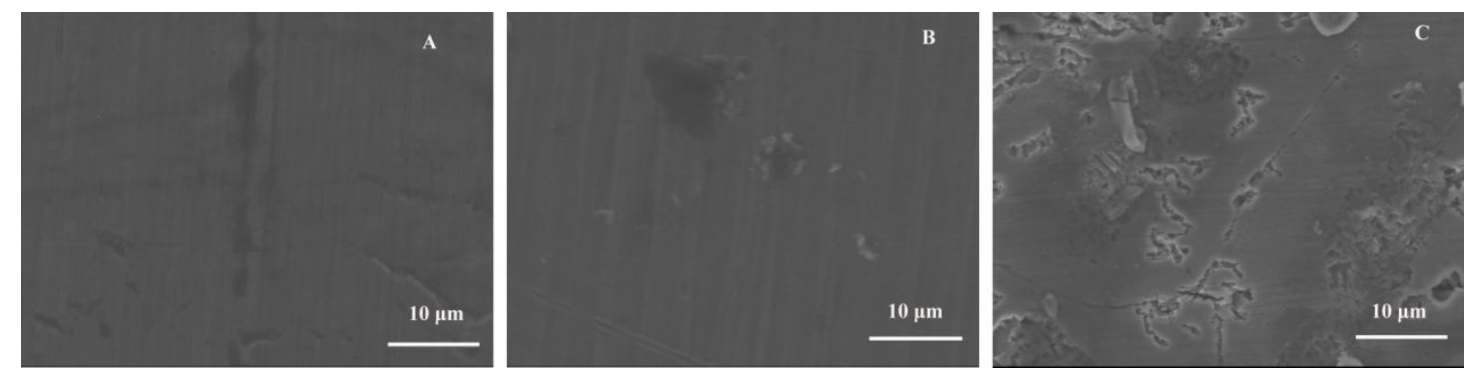

Figure S16 SEM of of Al in different environment. (A) without being treated; (B) after $200 \mathrm{CV}$ cycles; (C) after $500 \mathrm{CV}$ cycles.

\section{EIS of batteries using different electrolytes}

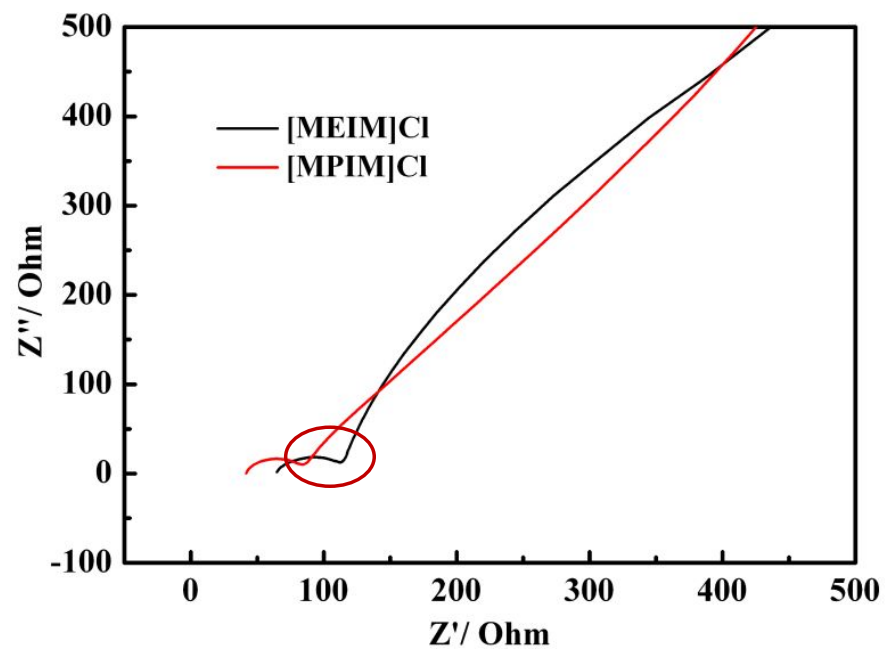

Figure S17 EIS of batteries using different electrolyte 